www.jmscr.igmpublication.org

Impact Factor 3.79

ISSN (e)-2347-176x

crossref DOI: _http://dx.doi.org/10.18535/jmscr/v3i10.05

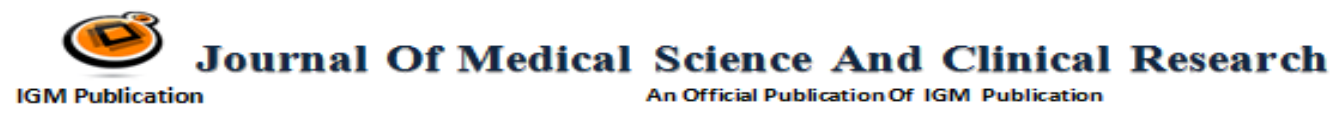

\title{
Pulmonary Hypertension as Presenting Manifestation of Systemic Lupus Erythematosus
}

\author{
Authors \\ Dr L.Venu Gopal ${ }^{1}$, Rakesh Reddy $R^{2}$, Swetha $D^{3}$, Dr Dilip M Ram Pure \\ ${ }^{1}$ Associate Professor, Dept of General Medicine, Mamata Medical College \& General Hospital- \\ Khammam, Telangana State \\ ${ }^{2}$ Post Graduate, Dept of General Medicine, Mamata Medical College \& General Hospital- \\ Khammam, Telangana State \\ ${ }^{3}$ Post Graduate, Dept of General Medicine, Mamata Medical College \& General Hospital- \\ Khammam, Telangana State \\ ${ }^{4}$ Professor and Head of Dept. of General Medicine, Mamata Medical College \& General Hospital- \\ Khammam, Telangana State \\ Corresponding Author \\ Dr Swetha. Dandamudi \\ Departments of General Medicine, Mamata General Hospital, Khammam, Telangana-507002, India \\ Email: dandamudiswetha@gmail.com Ph no-9866151977 \\ Pulmonary hypertension as presenting manifestation of SLE is extremely rare. Here we report a case of 29 year \\ old woman presenting with progressive shortness of breath associated with pedal edema which on detailed \\ examination found to be secondary to pulmonary hypertension .Further examination of patient fulfilled \\ KEY WORDS: Systemic Lupus Erythematosus (SLE), Pulmonary Hypertension(PH).
}

\section{ABSTRACT} diagnostic criteria of SLE

\section{INTRODUCTION}

Pleura-pulmonary manifestations of SLE present 4-5\% of patients at presentation. These include pleural effusion, pulmonary infections, alveolar hemorrhages, diffuse interstitial lung disease, pulmonary embolism and pulmonary hypertension. $\mathrm{PH}$ is third leading cause of death in $\mathrm{SLE}^{(4)}$. $\mathrm{PAH}$ is defined as mean arterial pressure more than $25 \mathrm{mmHg}$ on right heart catheterization. It is associated with many autoimmune diseases like SLE, systemic sclerosis, scleroderma. SLE associated PAH is a rare condition and uncommon cause of death after cardiovascular disease, infection, renal failure and non hodgkins lymphoma. It usually occurs 3-5 yrs after disease onset, it is a life threatening condition due to insidious nature of the disease.

\section{CASE REPORT}

We report a case of 29 year old female who presented to emergency department with complaints of progressive shortness of breath on exertion since 3 weeks associated with bilateral pitting type of ankle edema. History revealed that 
she used to get waxes and wanes of dyspnea that interfere with daily activity and polyarthritis involving hand joints of 6 months duration. Physical examination revealed raised jvp, left parasternal heave of grade $2 / 3$ which is sustained. Auscultation revealed pansystolic murmur of grade 3/6 and loud p2. Electrocardiogram showed poor R-wave progression and persistence of the $\mathrm{S}$ wave from V3 through V6. Transthoracic echo revealed dilated right atrium and right ventricle with severe tricuspid regurgitation, an estimated systolic arterial pressure of $90 \mathrm{~mm}$ of $\mathrm{Hg}$. Right heart catheterisation revealed systolic pulmonary arterial pressure of $76 \mathrm{~mm}$ of $\mathrm{Hg}$ and mean pulmonary arterial pressure of $52 \mathrm{~mm}$ of $\mathrm{Hg}$. Connective tissue screening revealed rheumatoid factor- positive, Anti smith -positive, Anti cardiolipin antibodies-positive, Anti dsDna positive, ANA - moderately positive with speckled pattern. Diagnosis of SLE was made as it fulfilled American college of Rheumatology criteria.
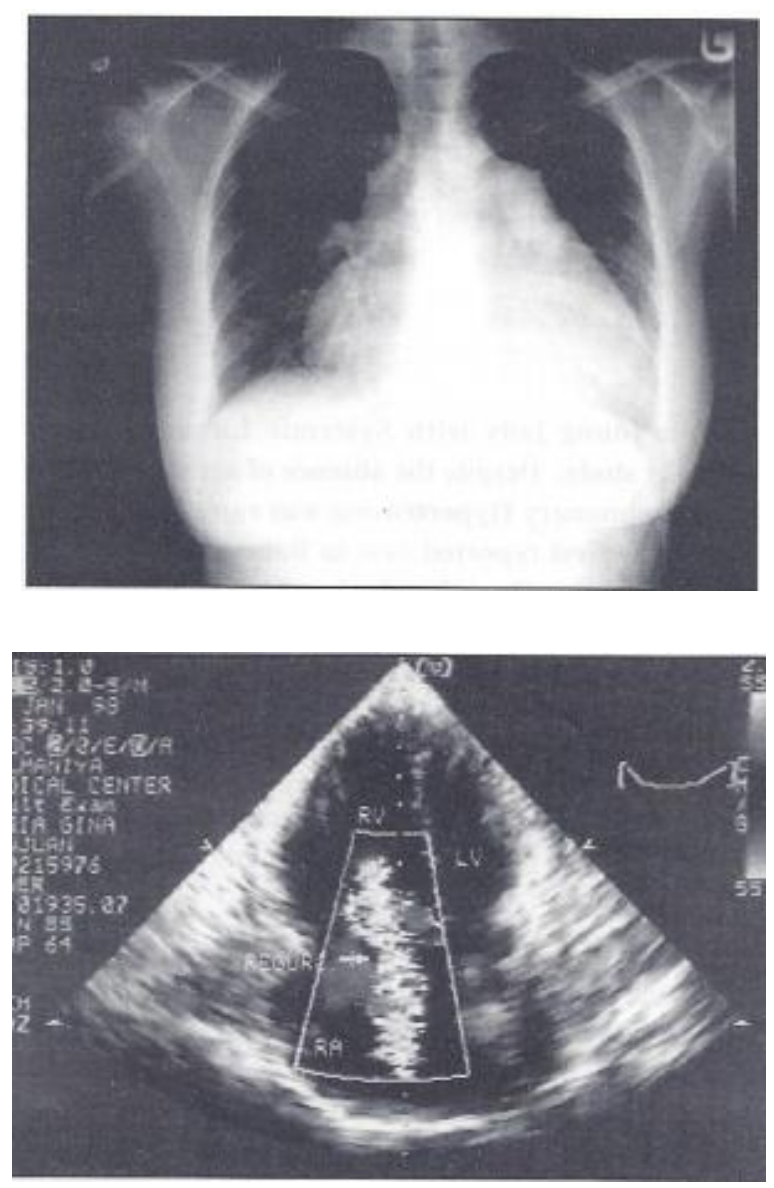

\section{DISCUSSION}

Systemic lupus erythematosus is an autoimmune disease, events that considered in pathogensis of SLE is autoimmune vasculitides, thromboembolic events, and increased ratio of vasoconstrictor to dilator ratio. prominent role of immunological events in endothelial damage is supported by response to immunosuppressive therapy in earliest phase of SLE ${ }^{(6)}$. Thromboembolic events in SLE contribute to small vessel damage as indicated by presence of anticardiolipin antibodies ${ }^{2,4}$. This cardiolipin antibodies can trigger on inflammation by binding to endothelial cells and monocytes by specifically targeting a multiprotiensignaling complex toll like receptors and annexin which ultimately activate TNF receptors, IL-1 receptors and nuclear factor kappa light chain enhancers. These ultimately lead to irreversible changes in and around small vessels refered as vascular remodeling.

PH may occur at any stage during SLE with prevalence being 1-4\% and its presentation in SLE is varied. Early therapy is essential because advanced disease may be less responsive to therapy. Based on data obtained with cardiac catheterisation, the gold standard for the diagnosis of PAH, the SLE-PAH prevalence has been estimated to range between 0.005 to $14 \%$. This wide range of reported percentages may be due to different cut-offs $(\mathrm{mmHg})$ adopted for the diagnosis in the different studies - i.e. $25 \mathrm{mmHg}$ vs. $30 \mathrm{mmHg}$ and/or different patients ethnicity .

The prognosis of patients with $\mathrm{PH}$ has been reported very poor and duration of survival from onset of PH was within 2 years. Early diagnosis and treatment to lower $\mathrm{PH}$ may improve the prognosis of patient. ${ }^{(1)}$ Heart lung transplantation and lung transplantation for PAH resulted in long term survival $^{(5)}$

The case reported here illustrates several points. Severe pulmonary hypertension in association with SLE may present at a time when other manifestations of SLE are quiescent. Our patient also illustrates the point that patients with SLE may present with pulmonary hypertension without 
any evidence of parenchymal lung disease by chest $x$ ray.

\section{CONCLUSION}

SLE as a cause of pulmonary hypertension should be suspected and evaluated accordingly in all patients particularly young females which is most common age group for both these conditions.

\section{REFERENCES}

1. M.J, YT, TA, et al. long term retrospective study of patient with connective tissue disease accompanied by pulmonary hypertension. Ryumachi 1993;33;29-36

2. winslow TM, ossipov MA, Fazio GP, et al. five year follow up study of prevalence and progression of the pulmonary hypertension in systemic lupus erythomatosus. AM heart J 1995;129:510-5

3. Greon $H$, bootsma $H$, postma DS, et al. primary pulmonary hypertension in a patient with systemic lupus erythematosus; partial improvement with cyclophosphamide . J Rhematol 1993;20:1055-7

4. Kim WU, Min JK, Lee SH, et al. cause of death in patients with SLE: a single centre retrospective study. ClinExperRheumatol. 1999; 17:539-545

5. Hutter JA, Despins P, Higenbottam T, et al. heart lung transplantation: better use of resource Am J Med. 1988;85:4-11.

6. Jais $\mathrm{X}$, Launy $\mathrm{D}$, Yaici $\mathrm{A}$, et al. immunosuppressive therapy in lupus and mixed connective tissue disease associated pulmonary arterial hypertension. Arthritis rheum. 2008;58:521- 531 